Provided for non-commercial research and education use. Not for reproduction, distribution or commercial use.

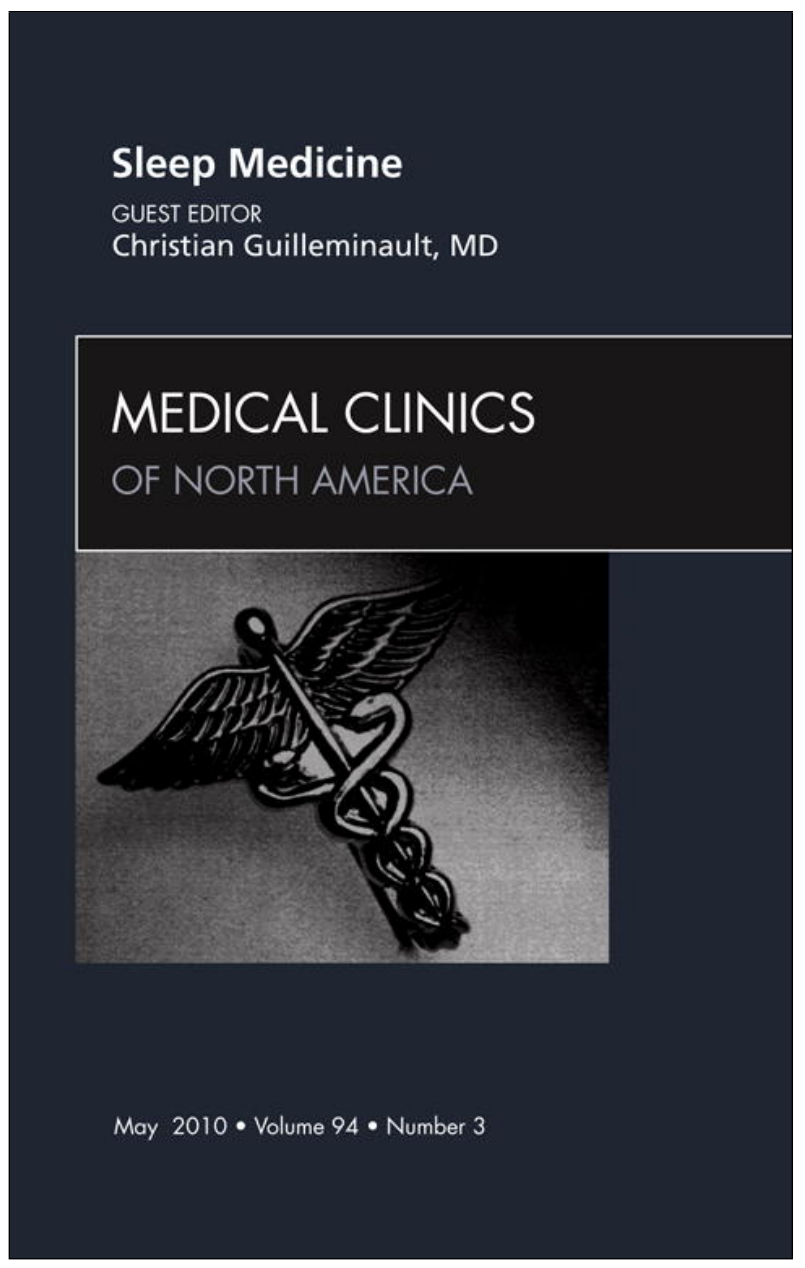

This article appeared in a journal published by Elsevier. The attached copy is furnished to the author for internal non-commercial research and education use, including for instruction at the authors institution and sharing with colleagues.

Other uses, including reproduction and distribution, or selling or licensing copies, or posting to personal, institutional or third party websites are prohibited.

In most cases authors are permitted to post their version of the article (e.g. in Word or Tex form) to their personal website or institutional repository. Authors requiring further information regarding Elsevier's archiving and manuscript policies are encouraged to visit:

http://www.elsevier.com/copyright 


\section{Orthodontics and Obstructive Sleep Apnea in Children}

Paola Pirelli, DDs ${ }^{a, b, *}$, Maurizio Saponara, $\mathrm{MD}^{\mathrm{c}}$, Chiara De Rosa, DDs ${ }^{a}$, Ezio Fanucci, MD ${ }^{d}$

\section{KEYWORDS}

- Obstructive sleep apnea syndrome • Rapid maxillary expansion

- Nasal septum deviation • Polysomnography

The association between obstructive sleep apnea syndrome (OSAS), maxillofacial malformations, and malocclusions has attracted more attention in the recent past. In several reports, Guilleminault, ${ }^{1-3}$ from the Stanford University Medical School, has underlined the importance of multidisciplinary collaboration in the treatment of breathing-related sleep disorders and has emphasized that children suffering from mild OSAS commonly present with airway obstruction related to nasal septum deviation associated with a narrow upper jaw. Also, he has mentioned that in children with obstructive sleep apnea (OSA), the role of craniofacial abnormalities and the impact of orthodontics have often been overlooked until now, despite their impact on public health. Treatment of OSA by rapid maxillary expansion (RME) was mentioned by Cistulli and colleagues. ${ }^{4}$ At the third International Congress of Craniofacial and Maxillofacial Distraction Paris, France, June 2001, and the seventh World Congress on Sleep Apnea Helsinki, Finland, June 2003, Pirelli had several presentations on the potential role of RME in children with abnormal breathing during sleep, work that led to the first full report on the treatment of pediatric OSA by RME. ${ }^{5}$ This report was based on a multidisciplinary collaboration, and it clearly showed that the contribution from different specialists could lead to effective therapy when considering the treatment of a disorder as complex as pediatric OSA. Particularly interesting were the correlations found between OSAS, malocclusion, and maxillofacial malformations. In fact, many patients with OSAS show craniofacial abnormalities in both jaws as well as alteration in the skeletal structure of the respiratory dynamic space. ${ }^{3-6}$ Nasal septum alteration reduces airflow and increases resistance to nasal breathing. ${ }^{6,7}$ Micrognathia and

\footnotetext{
a Department of Odontostomatological Sciences, University of Tor Vergata, Rome, Italy

b Via Tomacelli 103, Rome 00186, Italy

c Department of Neurology and Otolaryngology, University "La Sapienza", Rome, Italy

d Department of Diagnostic Imaging Interventional Radiology, University of Tor Vergata, Rome, Italy

* Corresponding author. Via Tomacelli 103, Rome 00186.

E-mail address: p.pirelli@gmail.com
} 
nasal obstruction are among the risk factors for OSAS. ${ }^{3-7}$ Maxillary impaired development results in a decrease in the size of the nasomaxillary complex and then of the nasopharyngeal airway dimension (as presented at the 81st congress of the European Orthodontic Society Amsterdam, The Netherlands, June 2005; "Therapeutic effects of R.M.E."). Nasal septum deviations are responsible not only for an asymmetric distribution of intranasal spaces but also for the internal structural alteration of the turbinates, more particularly the nasal inferior turbinate, which in turn causes a reduction of total airflow. ${ }^{8-11}$ Considering that a significant number of children suffering from mild OSAS show an obstructive phenomenon with nasal septum deviation with or without turbinate hypertrophy, associated with a narrow upper jaw, ${ }^{9}$ this report describes how rapid maxillary expansion may improve the patency of the nasal airway and to which extent it may improve pediatric OSA.

\section{MATERIAL AND METHODS}

Of a sample of 150 patients, the authors selected 60 children (38 males and 22 females) between 6 and 13 years of age (average 7.3 years) who were seen for oral breathing, snoring, and history of nocturnal apneas.

Selection criteria included no adenotonsillar hypertrophy, body mass index less than $24 \mathrm{~kg} / \mathrm{m}^{2}$, and malocclusion characterized by upper jaw contraction. Patients underwent an ear-nose-throat (ENT) visit with the following tests: audiometry, tympanometry with tubaric functionality maneuvers, active anterior rhinomanometry, nasal fibroscopy, and daytime sleepiness questionnaire. Polysomnography was performed with recording of 19 channels.

Sleep-wake states were based on electroencephalograms, electro-oculogram, electromyogram, electrocardiogram, body position, nasal and oral flow, thoracic and abdominal movement, snoring noise, and pulse oximetry. Polysomnograms were analyzed following the Rechtschaffen and Kales International Criteria for sleep-wake scoring and the American Academy for Sleep Medicine recommendation for the scoring and breathing events. ${ }^{12}$ Abnormal events were considered present if longer than 2 breaths in duration. Events were classified as apnea or hypopnea based on air flow and as obstructive, mixed, or central based on thoracoabdominal movements and air flow. An orthognathodontic investigation was performed using radiographs that included not only the usual examination, that is, posteroanterior cephalographs and intraoral radiographs, but also CT scans. All the investigations, except CT Dentascan, were carried out (1) before the orthodontic therapy (pretreatment T0); (2) 1 month (T1) after therapy, with the device still in place; and (3) 4 months after the end of orthodontic treatment, which lasted 6 to 12 months. CT Dentascan was performed only before treatment (T0) and after about 20 to 30 days (at end of active expansion [T1]) with the device still in place.

To reduce radiation exposure, a low-dosage CT Dentascan protocol was used. The study was performed using the CT scanner Lightspeed Advantage (GE Medical System Milwaukee, WI, USA).

The experimental study was approved by the Human Care Committee, and all the patients signed an informed consent.

\section{ORTHODONTIC EXAMINATION}

The clinical orthodontic examination carried out on the basis of the authors' diagnostic criteria ${ }^{13,14}$ gave the following results:

- Extraoral examination: presence of the typical facies of oral breathers characterized by (1) flattening of the middle-facial-third, (2) labial incompetence with hypotonia of the upper lip and with a resulting increase in the nasal-labial angle; 
- Intraoral examination: presence in all cases of narrowness of the upper jaw with an ogival palate pattern resulting from a high and narrow palatal arch. This narrowness was clinically present in most of the treated cases with a malocclusion characterized by unilateral or bilateral crossbite and often by an anterior crossbite.

The narrowness of the upper jaw was diagnosed clinically and confirmed by cephalometric assessment according to Ricketts parameters in posteroanterior cephalograms. ${ }^{15}$

The following measurements were evaluated

For nasal cavity diameters: NC-CN

And for maxillary diameters: JL-JR.

For the assessment of the increase in the maxillary cross section, 2 planes were used: for nasal cavity width NC-CN and for maxillary width JL-JR (bilateral points located at the depth of the concavity of the lateral maxillary contour at the junction of the maxilla and zygomatic buttress).

In addition, the interincisive space $A 1-1 A$ and the intermolar width $A 6-6 A$ were measured.

\section{RAPID MAXILLARY EXPANSION}

The RME procedure, successfully performed for many years in clinical practice, uses an orthodontic fixed appliance with an expansion screw, anchored on selected teeth. ${ }^{16}$ According to the phase of development of the teeth, the device is constructed using the first molars and permanent premolars as anchor teeth, whereas in the deciduous dentition, the second primary molars are selected, provided that they offer the stability required for appropriate treatment.

The device is made up of a central expansion screw with 4 arms: 2 front arms and 2 back arms of length $1.5 \mathrm{~mm}$. Two types of screw are used: the Leone A0620/13 (Italy) and the Forestadent 1671326L (Germany); palatal split screw type "S" is used for especially narrow palates. The device must satisfy some fundamental construction criteria. The force is applied through the anchor teeth so as to act directly on the suture, without any undesired tipping of the teeth. This application produces a transpalatal force that exceeds physiologic levels that could produce orthodontic movement. At the same time, the midpalatal suture opens and orthopedic movement of the maxillae occurs.

Osteoid appears at the borders of the palatal processes, and a normal mineralized suture reforms after 3 to 4 months. ${ }^{16-21}$ Valid treatment is possible only on proceeding as outlined earlier as the maxillary expansion must not be due to dental arch tipping but due to an actual increase in the palatal transversal diameters. This increase can be achieved only through changes induced in the midpalatal suture. The device must not be bulky but must be strong and fitting well on the anchor teeth; the expansion screw must be placed as high as possible in the palate. The effectiveness of this maneuver depends also on the amount of force applied and on the duration of application of the force.

\section{ACTIVATION SYSTEM}

The screw activation system the authors use works as follows ${ }^{17,18}$ :

- On the first day, morning and evening, 3 consecutive activations are applied at 10-minute intervals.

- From the second day onwards, only 1 activation is applied every morning and evening. 
The comparison of an occlusal intraoral radiograph obtained at T0 with another one at 3 days from the beginning of activation allows us to verify the opening of the midpalatal suture and thus to continue expansion safely. Active expansion ranges from 10 to 20 days according to individual needs.

As in general practice, the device was well tolerated by all the patients in the presented study. All patients and their parents had been previously briefed on the behavior, diet, and oral hygiene needed to be followed for this particular device to avoid any complication that could interfere with the expansion maneuver.

\section{STATISTICAL ANALYSIS}

Data were analyzed with the statistical package for the social sciences program. The Wilcoxon signed rank test was used on data obtained before and after the study to assess changes caused by the procedure. The Wilcoxon signed rank test examines information on the differences and on the magnitude of difference between the 2 studied parameters (before and after treatment); it is the most powerful "sign test."

\section{RESULTS}

\section{Orthopedic/Orthodontic Results}

All the changes induced by RME on the upper jaw and adjacent structures were analyzed by posteroanterior cephalometric evaluation in T0, T1, and T2 and by CT Dentascan at T0 and T1. This evaluation is the most reliable way to assess the increase in the maxillary cross section. In fact, studies assessing the increase in upper dental arch width on cast models can be influenced by dental tipping that can show increases not actually corresponding to skeletal changes.

The Ricketts parameters were adopted for the posteroanterior cephalometric evaluation (Fig. 1). ${ }^{5}$ In all treated cases, an opening of the midpalatal suture was obtained; the result was confirmed by intraoral occlusal radiographs (Fig. 2), posteroanterior cephalograms (Fig. 3), and CT Dentascan The evaluation of the variations of the maxillary width shows an increase, confirming that the RME maneuver directly influences the skeleton with the expansion of the midpalatal suture (Fig. 4). This maneuver is responsible for the expansion of both maxillas, with an average cross-sectional increase (JL-JR) of $5.91 \pm 0.7 \mathrm{~mm}$. The study of the upper intermolar distance (A6$6 A)$ shows an average increase of $8.18 \pm 0.3 \mathrm{~mm}$. The interincisive space $(A 1-1 A)$,
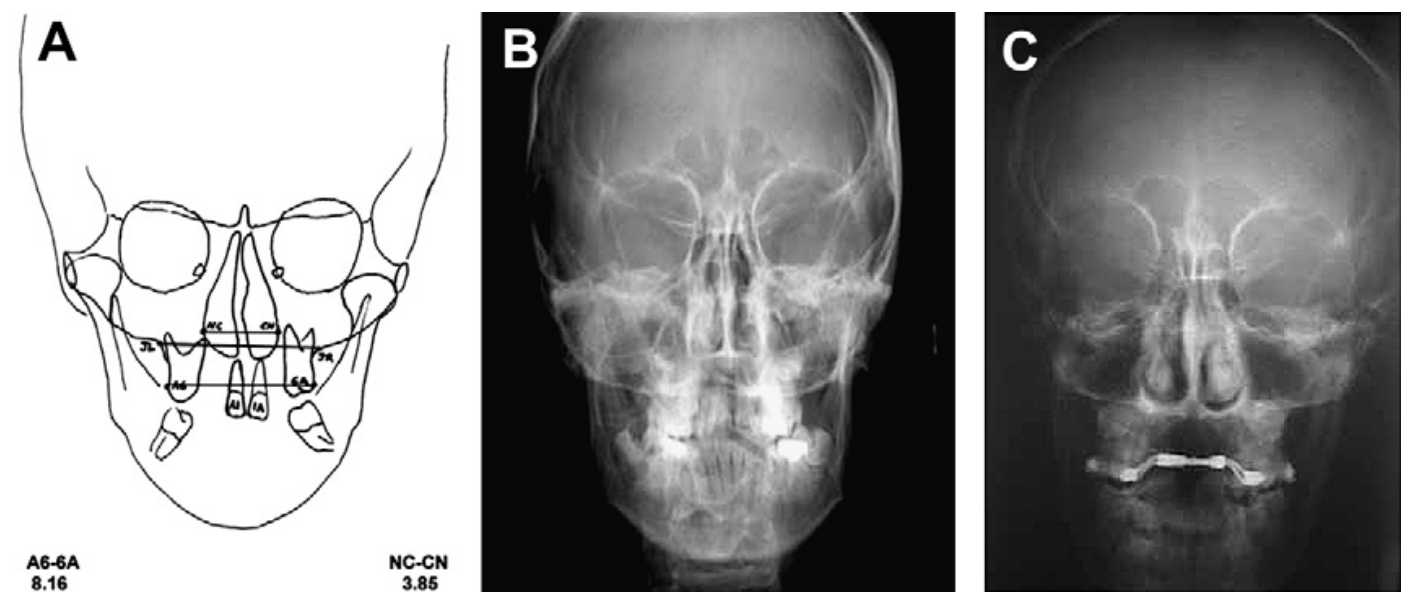

Fig. 1. ( $A-C)$ Cephalometric assessment before and after RME (mean data values). Anatomic changes in whole sample: all cross-sectional diameters increased at intermaxillar and intermolar level. Nasal cavities and interincisive spaces increased in width. 


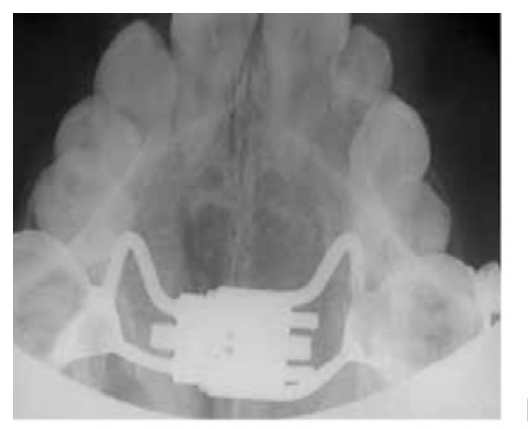

PRE R.M.E

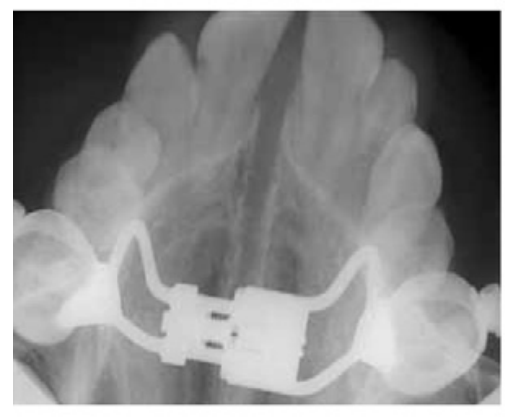

POST R.M.E. ( 1 WEEK)

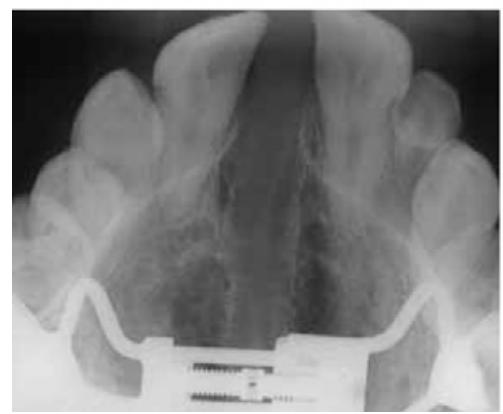

POST R.M.E. (3 WEEKS)

Fig. 2. Intraoral radiograph before and after RME.

hallmark of the midpalatal suture opening, was present in all treated cases, with an average opening of $4.72 \pm 0.2 \mathrm{~mm}$. This space gradually disappears, possibly because of transseptal fiber pull, which brings the fibers together. The increase in maxillary cross section is also shown by the study of the nasal cavities (NC-CN) that are widened by the maneuver with an average increase of the pyriform opening of $3.85 \pm 0.3 \mathrm{~mm}$.

\section{Results of ENT Examination}

During the first (baseline) examination (TO) the selected sample reported the following results:

- Pharyngoscopy: 42 patients had previously had adenotonsillectomy surgery; there were normotrophic palatal tonsils in 18 cases.

- Posterior rhinoscopy with nasal fibroscopy: in all 60 cases, no significant adenoid lymphatic tissue or other obstructive causes were noted.

- Anterior rhinoscopy: nasal septum deviation with hypertrophy of the inferior turbinates was present in 41 cases, and 19 cases had normal inferior nasal turbinates.

- Active anterior rhinometry: that is, based on a nasal resistance value greater than 1.8 at a pressure of $75 \mathrm{~Pa}$ with a unilateral impairment that was considered as pathologic in another 10 cases.

- Allergological tests with prick test: negative outcome for major permanent and seasonal allergens in all subjects. 

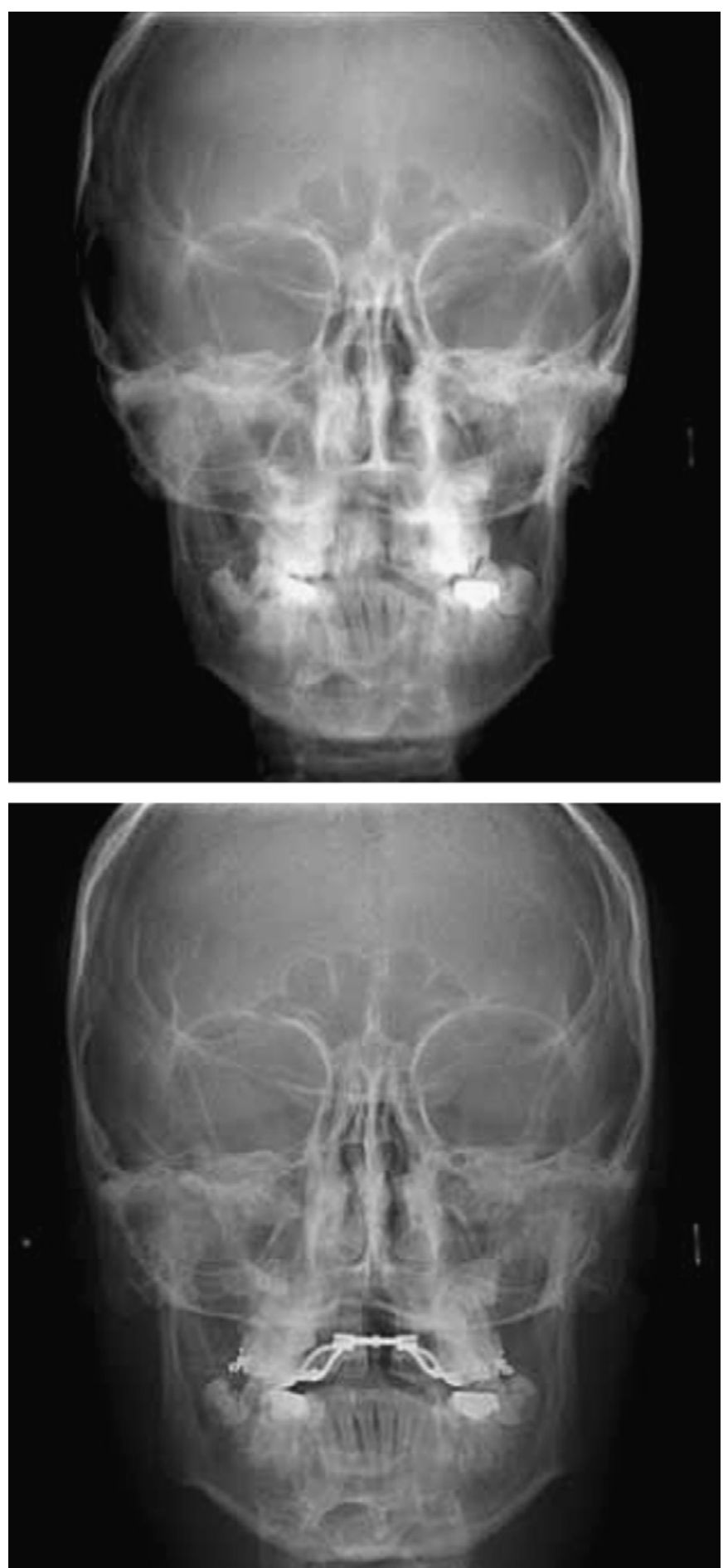

Fig. 3. Case of teleradiograph in posteroanterior view taken pre-RME (top) and post-RME (bottom).

- Audiometric tests: 14 patients showed moderate conductive hearing loss (15-30 $\mathrm{dB} H \mathrm{HL})$, unilateral in 5 cases, bilateral in 9 cases.

- Tympanometric tests with tubaric functionality maneuvers: type $\mathrm{C}$ curve with tubaric deficit (compliance at pressure values $<100 \mathrm{~mm} \mathrm{H}_{2} \mathrm{O}$ ) was found in 16 children.

\section{POLYSOMNOGRAPHY}

Baseline: the apnea-hypopnea index $(\mathrm{AHI})$ values of 60 patients ranged from 6.1 to 22.4 events per hour (average 16.3) (normal value<5). Patients were subdivided into 

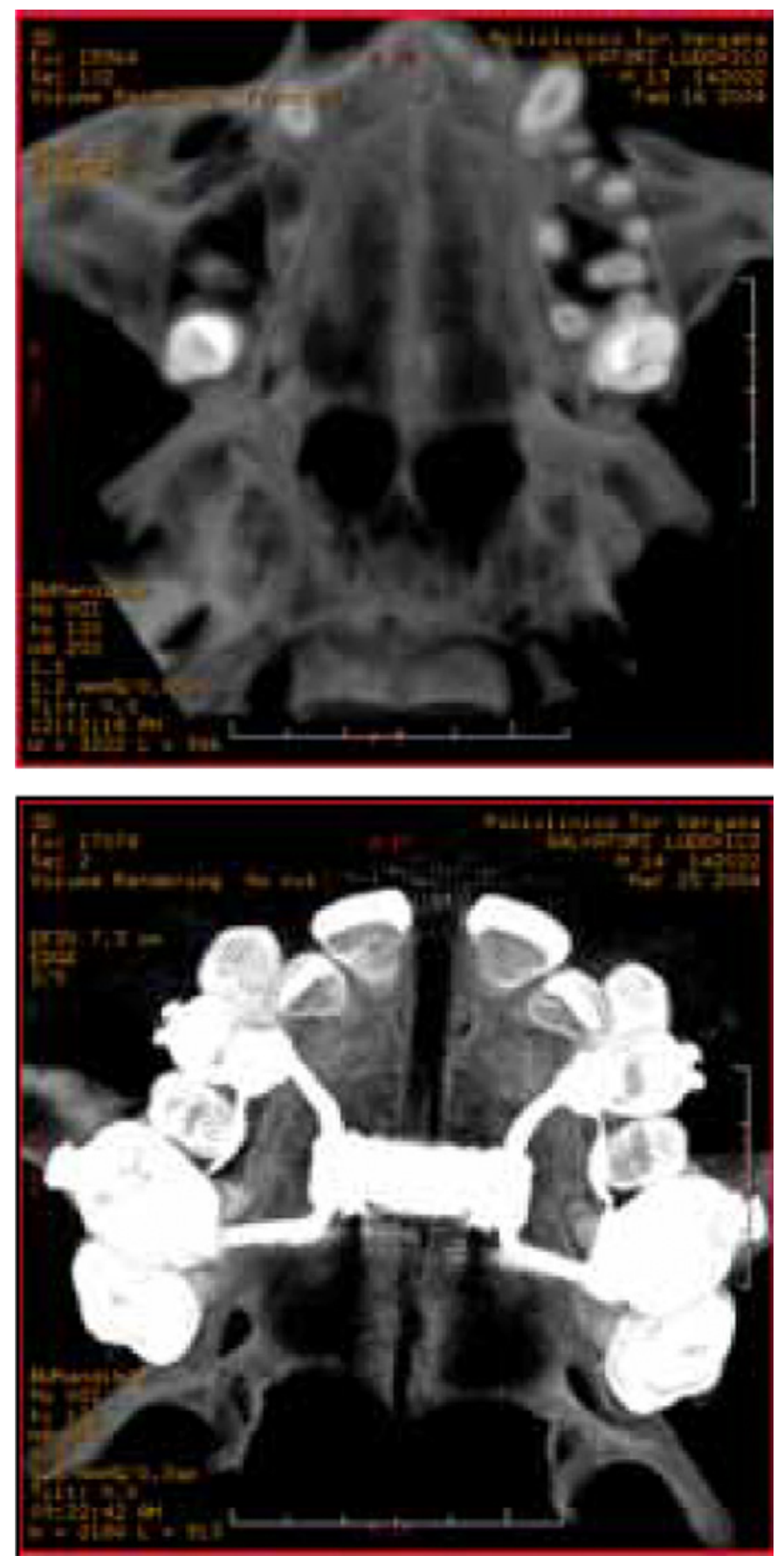

Fig. 4. CT volume rendering of maxilla pre-RME (top) and post-RME (bottom).

3 groups: group A had AHI values from 5 to 10, average 8.3 (16 cases); group B had $\mathrm{AHI}$ values between 11 and 15, average 12.88 (35 cases); group $\mathrm{C}$ had AHI values between 16 and 22.4, average 19 (9 cases) (Table 1).

After 4 months of orthodontic treatment with the device still in place (T1) nasal functional and polysomnographic tests showed the following:

- Out of the 36 cases with bilateral nose-breathing deficit, 28 went back to normal; in 8 cases the deficit was unilateral, and in 2 cases the deficit had improved but was still present; all of the 10 cases of unilateral deficit were within physiologic limits.

- Audiometric tests, tympanometry, and tubaric functionality tests: 7 of the 14 patients with tubaric disease healed without associated medical therapy, and 7 patients underwent mucolytic and/or cortisone therapy. 


\begin{tabular}{|c|c|c|c|}
\hline \multicolumn{4}{|c|}{$\begin{array}{l}\text { Table } 1 \\
\text { Polysomnographic data in } 60 \text { children }\end{array}$} \\
\hline & T0 & $\mathrm{T1}$ & $\mathrm{T} 2$ \\
\hline Obstructive AHI & $\begin{array}{l}\text { Range, } 6.1-22.4 \\
\text { Average, } 16.3 \pm 2.5\end{array}$ & $\begin{array}{l}\text { Range, } 0-9.1 \\
\text { Average, } 8.3 \pm 2.3\end{array}$ & $\begin{array}{l}\text { Range, } 0-26 \\
\text { Average, } 0.8 \pm 1.3\end{array}$ \\
\hline Nadir $\mathrm{SP}_{2}(\%)$ & $77.9 \pm 8.4$ & $90.2 \pm 5.7$ & $95.4 \pm 1.4$ \\
\hline $\begin{array}{l}\text { Duration of Longest Obstructive } \\
\text { Apneas }\end{array}$ & $39.8 \pm 17.2$ & $24.3 \pm 12.3$ & $12.1 \pm 6.5$ \\
\hline $\begin{array}{l}\text { Duration of Desaturation } \\
\text { (S302<92\%) ass\% TST } \\
\end{array}$ & $18.5 \pm 3.2$ & $5.8 \pm 1.3$ & $1.3 \pm 1.4$ \\
\hline Sleep Efficiency (\%) & $88.5 \pm 9.1$ & $88.9 \pm 5.7$ & $89.8 \pm 8.5$ \\
\hline
\end{tabular}

Note the significant improvement in all the functional parameters achieved at T2. All data are displayed as mean \pm standard deviation.

Abbreviations: TST, total sleep time; T0, before any orthodontic therapy; T1, after 4 weeks with the device; T2, 4 months after the end of the orthodontic treatment.

- Polysomnography (Figs. 5 and 6): groups A and B present a normalization of recording, with $\mathrm{AHI}$ less than 5 . In group $\mathrm{C}, 5$ cases had an $\mathrm{AHI}$ less than 5 , and in the last 4 cases, a significant improvement with AHI between 6.6 and 8.4 events per hour was noted.

Four months after end of the orthodontic treatment (T2), all tests showing a normalization of functional examinations were confirmed.

- Active anterior rhinometry: the 8 cases with residual unilateral deficit showed normal results; the 2 cases of group $C$ with bilateral deficit continued to improve although physiologic levels were not reached.

- Polysomnography: the cases of group $\mathrm{C}$ with residual abnormal breathing events $(\mathrm{AHI}<5)$ were also normalized (see Table 1).

\section{STATISTICAL FINDINGS}

The baseline rhinomanometric data showed a statistically significant difference with respect to those measured at 2 and 4 months (Wilcoxon $Z=-4.86, P=.000$; Wilcoxon $Z=-5.39, P=.000$, respectively). The difference between rhinomanometric data at 2 and 4 months was also statistically significant (Wilcoxon $Z=-4.86, P=.000$ ).

The difference between baseline $\mathrm{AHI}$ and that at 2 and 4 months was also statistically significant (Wilcoxon $Z=-4.0, P=.000$; Wilcoxon $Z=-5.15, P=.000$, respectively). The difference between $\mathrm{AHI}$ at 2 and 4 months was also statistically significant (Wilcoxon $Z=-2.0, P=.046$ ).

\section{DISCUSSION}

The results obtained on the 60 patients show that the RME therapy widens nasal fossa and releases the septum, thus restoring a normal nasal airflow with disappearance of obstructive sleep-disordered breathing.

The improvement can be clearly linked to the skeletal expansion caused by the maneuver performed on the suture.

CT images before and after RME therapy confirm that the expansion occurs not only in the maxillary arch but also in the nasal cavity (Fig. 7): the widening of the nasal fossa and the septal release restore normal airflow. This anatomic change brings about an increased patency of the upper airway. This patency is the basis for the positive 
Patient Information pre- RME

Name: $\quad$ C.G. IN t0

Sex : $\quad M$

Age : 8 years

Date of study: $20 / 10 / 03$ at 20.09.35

Duration (TSIT): 645 Min $\quad$ Acquisition: 984

Apnea/ Hypopnea

\begin{tabular}{|l|c|c|c|c|}
\cline { 2 - 5 } \multicolumn{1}{c|}{} & Number & $\begin{array}{c}\text { Mean } \\
(\mathrm{sec})\end{array}$ & $\begin{array}{c}\text { Max } \\
(\mathrm{sec})\end{array}$ & $\begin{array}{c}\text { Index } \\
\text { \#/hr (TSIT) }\end{array}$ \\
\hline Central & 7 & 15.3 & 20.5 & 0.7 \\
\hline Obst & 8 & 15.3 & 20.5 & 0.7 \\
\hline Mixed & 3 & 14.8 & 17.5 & 0.3 \\
\hline Hypop & 107 & 25.2 & 60 & 10 \\
\hline Total & 125 & 23.7 & 60 & 11.6 \\
\hline
\end{tabular}

Oximetry

\begin{tabular}{|c|c|}
\hline$<50 \%(\min )$ & 0 \\
\hline$<60 \%(\min )$ & 0 \\
\hline$<70 \%(\min )$ & 0 \\
\hline$<75 \%(\min )$ & 0 \\
\hline$<80 \%(\min )$ & 0 \\
\hline$<85 \%(\min )$ & 0 \\
\hline$<90 \%(\min )$ & 0 \\
\hline$<95 \%(\min )$ & 5 \\
\hline Average $(\%)$ & 98 \\
\hline Desat Index (\#hr TSIT) & 6.5 \\
\hline
\end{tabular}

Body position

\begin{tabular}{|c|c|c|}
\hline & Supine & Non- Supine \\
\hline Time (min) & 550.4 & 94.6 \\
\hline CA (\#) & 7 & 0 \\
\hline OA (\#) & 7 & 1 \\
\hline MA (\#) & 3 & 0 \\
\hline HYP (\#) & 97 & 10 \\
\hline Index (\#/hr) & 12.4 & 7 \\
\hline Desats (\#) & 61 & 8 \\
\hline
\end{tabular}

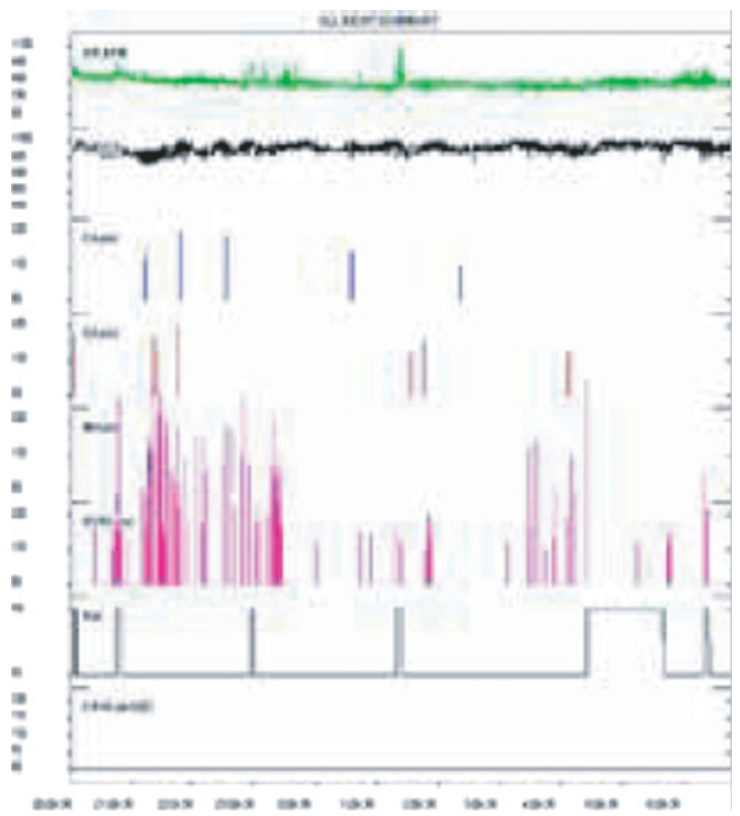

Fig. 5. Example of polysomnographic sheet raised by a patient before RME therapy (T0). The AHI value was 11.6 (normal value $<5$ ). 
Pirelli et al

Patient Information

$\begin{array}{lll}\text { Name : } & \text { C.G. T1 } \\ \text { Sex }: & \text { M } \\ \text { Age }: & 08 \text { years } & \\ \text { Date of study: } & 22 / 11 / 03 \text { at 20.24.03 } \\ \text { Duration (TSIT): } & 645 \text { Min Acquisition }: 356\end{array}$

Apnea / Hypopnea

\begin{tabular}{|l|c|c|c|c|}
\cline { 2 - 5 } \multicolumn{1}{c|}{} & Number & $\begin{array}{c}\text { Mean } \\
(\mathrm{sec})\end{array}$ & $\begin{array}{c}\text { Max } \\
(\mathrm{sec})\end{array}$ & $\begin{array}{c}\text { Index } \\
\text { \#/hr (TSIT) }\end{array}$ \\
\hline Central & 0 & 0 & 0 & 0 \\
\hline Obst & 0 & 0 & 0 & 0 \\
\hline Mixed & 0 & 0 & 0 & 0 \\
\hline Hypop & 12 & 26.8 & 58.5 & 1.1 \\
\hline Total & 12 & 26.8 & 58.5 & 1.1 \\
\hline
\end{tabular}

Oximetry

\begin{tabular}{|c|c|}
\hline$<50 \%(\mathrm{~min})$ & 0 \\
\hline$<60 \%(\mathrm{~min})$ & 0 \\
\hline$<70 \%(\mathrm{~min})$ & 0 \\
\hline$<75 \%(\mathrm{~min})$ & 0 \\
\hline$<80 \%(\mathrm{~min})$ & 0 \\
\hline$<85 \%(\mathrm{~min})$ & 0 \\
\hline$<90 \%(\mathrm{~min})$ & 0 \\
\hline$<95 \%(\mathrm{~min})$ & 0.5 \\
\hline Average $(\%)$ & 99 \\
\hline Desat Index (\#hr TSIT) & 1.1 \\
\hline
\end{tabular}

\begin{tabular}{|c|c|c|}
\multicolumn{3}{c|}{ Body position } \\
\begin{tabular}{|c|c|c|}
\hline & Supine & Non- Supine \\
\hline Time (min) & 150.5 & 494.5 \\
\hline CA (\#) & 0 & 0 \\
\hline OA (\#) & 0 & 0 \\
\hline MA (\#) & 0 & 0 \\
\hline HYP (\#) & 0 & 12 \\
\hline Index (\#/hr) & 0 & 1.5 \\
\hline Desats (\#) & 0 & 12 \\
\hline
\end{tabular}
\end{tabular}

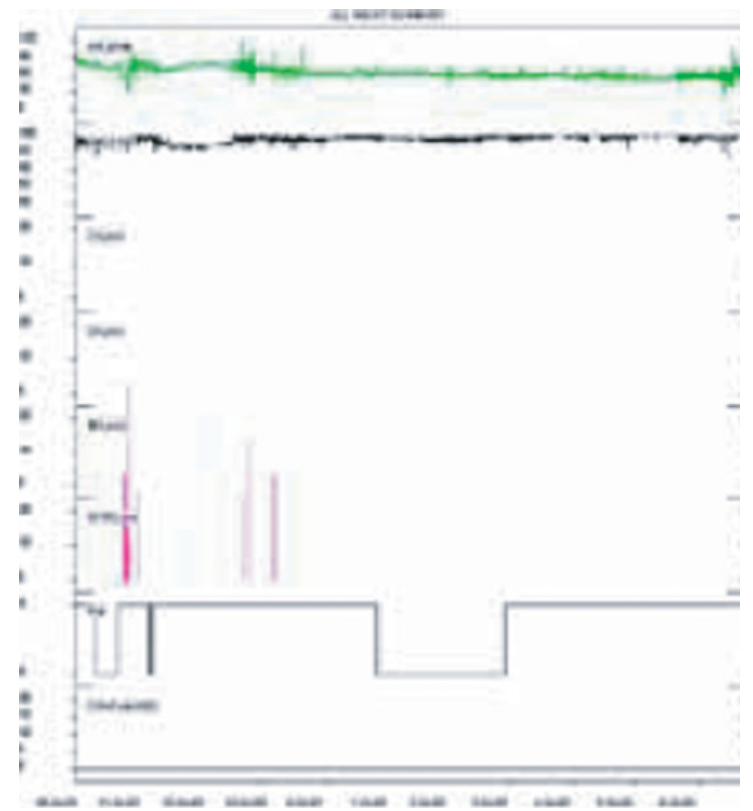

Fig. 6. Example of polysomnographic sheet raised by the same patient as in Fig 4 after 4 weeks of RME therapy (T1). Note the AHI value at 1.1. 

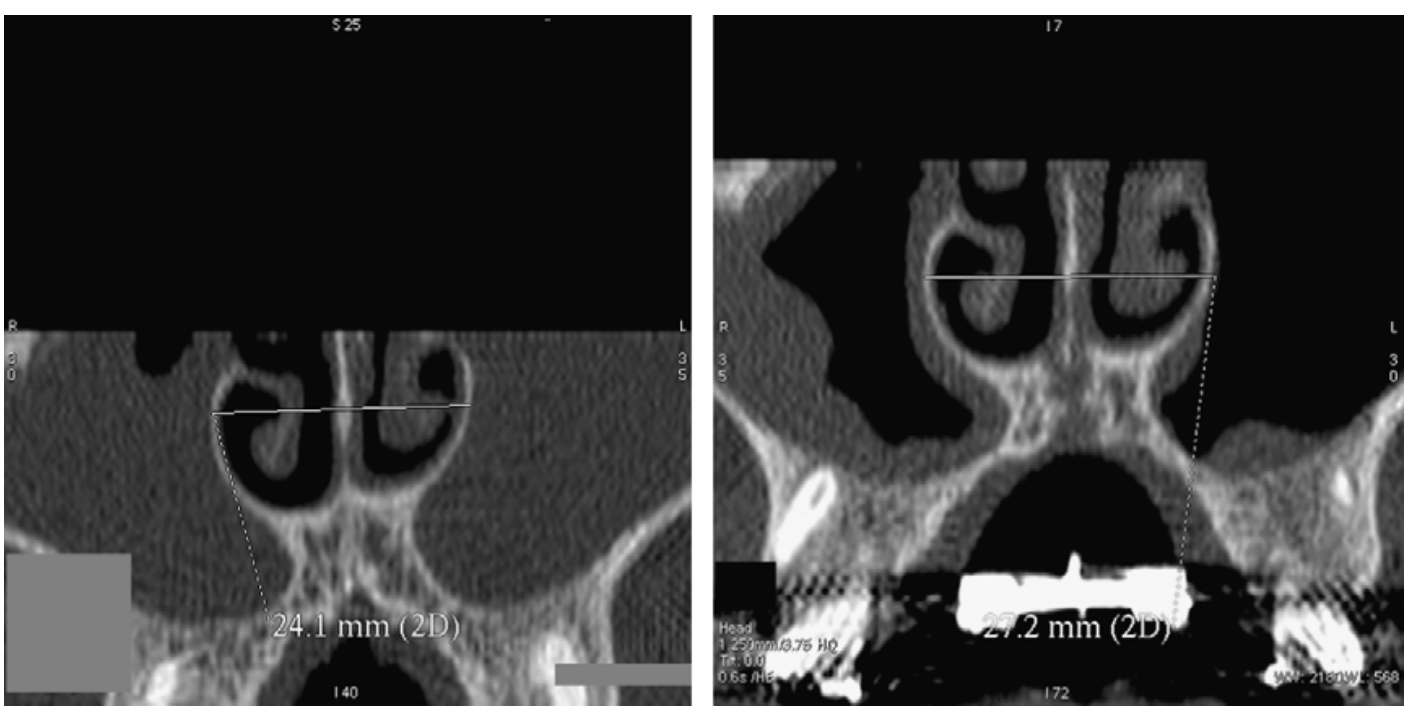

Fig. 7. TC Dentascan of nasal cavity increase before and after RME.

effects induced by the maneuver, and it acts on air exchange, with a net improvement of breathing disorders during sleep.

RME is a therapeutic procedure that the authors successfully performed for many years to obtain a skeletal expansion of the upper jaw. The anatomic criteria of this technique consist in the application of orthopedic forces, through particular procedures, on the midpalatal suture. This suture is mainly made up of compact bone laterally and fibrous tissue with fibroblasts, collagen fibers, and vessels centrally. ${ }^{20-22}$ Bone distraction is possible because of the very biology of the bone and can be achieved by applying heavy forces through the orthodontic device anchored onto the teeth. Bone distraction at the suture level causes an actual widening of the maxilla, increasing its cross section as well as the anatomic space of the nasal cavity. Radiographic findings clearly show how the RME maneuver separates the nasal and palatal bones. A substantial increase is reported at the cross-sectional level, with a relevant improvement in nasal airflow. Increasing of upper jaw cross section also clearly affects the nasal cavities, and it is a true anatomic change that brings about an increased patency of the upper airways. This increase is also the basis for the positive effects induced by the RME maneuver on the respiratory function. Associated orthodontic movements can also indirectly improve the oropharyngeal space by modifying the resting posture of the tongue.

Beginning in 1984, Timms ${ }^{19,23,24}$ has published several articles documenting the subjective and objective improvement of nasal resistance in 10-to-20-year-old subjects using rhinometry. However, he never made the connection between his findings and OSAS. Kurol and colleagues ${ }^{25}$ also reported improvement of nasal resistance in 10 prospectively studied children, aged 8 to 13 years, treated with RME. Warren and colleagues $^{26}$ who performed a prospective study on 16 children aged 10 to 14 years demonstrated improvement in $45 \%$ of cases. Probably RME would not be as successful in isolation in presence of adenotonsillar hypertrophy, and for this reason, children with enlarged adenoids and tonsils were not included in the authors' study.

Moreover, abnormal nasal resistance affects not only the maxilla but also the mandible. Despite the change in tongue position with RME, the gain may not be sufficient. The width of the mandible should be considered when RME is performed, because upper and lower teeth must be in apposition. Combined treatment on the maxilla and mandible, as recently presented by Guilleminault and $\mathrm{Li}^{27}$ may be necessary. Correction of upper jaw narrowness in children not only can resolve all OSAS 
cases but also may help avoid septoplasty in the adult by widening nasal cavities and straightening the septum.

The authors suggest careful evaluation of the maxillary skeleton base status as a possible common cause of OSAS and recommend resorting to RME therapy.

Orthodontists may play an important role in the interdisciplinary treatment of OSAS because a high percentage of patients with OSAS suffer from maxillary narrowness as the authors showed at the 17th Annual Meeting of American Academy of Dental Sleep Medicine (Baltimore, Maryland, USA, June 2008). In young patients, RME treatment can be effective and can have a favorable orthopedic role in modifying facial bony structures and in conditioning further developmental processes positively. ${ }^{28}$ The authors' experience shows that RME treatment has a positive effect on children affected by chronic snoring and OSA. By changing the anatomic structures, RME brings a functional improvement. It is always important to assess the condition of the upper jaw to consider RME therapy in the multidisciplinary treatment of OSAS in children.

\section{REFERENCES}

1. Guilleminault C, Khramtsov A. Upper airway resistance syndrome in children: a clinical review [review]. Semin Pediatr Neurol 2001;8(4):207-15.

2. Guilleminault C, Li KK, Khramtsov A, et al. Sleep disordered breathing: surgical outcomes in prepubertal children. Laryngoscope 2004;114(1):132-7.

3. Guilleminault C, Partinen M, Praud JP, et al. Morphometric facial changes and obstructive sleep apnea in adolescents. J Pediatr 1989;114(6):997-9.

4. Cistulli PA, Palmisano RG, Poole MD. Treatment of obstructive sleep apnea syndrome by rapid maxillary expansion. Sleep 1998;21:831-5.

5. Pirelli P, Saponara M, Guilleminault C. Rapid maxillary expansion in children with obstructive sleep apnea syndrome. Sleep 2004;27(4):761-6.

6. Harvold EP, Tomer BS, Vargervik K, et al. Primate experiments on oral respiration. Am J Orthod 1981;79(4):359 72.

7. Miller AJ, Vargervik K, Chierici G. Sequential neuromuscular changes on rhesus monkeys during the initial adaptation to oral respiration. Am J Orthod 1982;81(2): 99-107.

8. Rubin RM. Effects of nasal airway obstruction on facial growth. Ear Nose Throat J 1987;66(5):212-9.

9. Pirelli P, Saponara M, Attanasio G. Obstructive sleep apnea syndrome (OSAS) and rhinotubaric disfunction in children: therapeutic effects of RME therapy. Prog Orthod 2005;6(1):48-61.

10. Linder-Aronson S. Dimensions of face and palate in nose breathers and habitual mouth breathers. Odontol Revy 1969;14:187-200.

11. Pirelli P. Respirazione orale e sviluppo cranio facciale: importanza dell'approccio interdisciplinare [Oral breathing and cranio-facial development: role of the multidisciplinary approach]. Mondo Ortod 1996;21:265-75 [in Italian].

12. Sleep-related breathing disorders in adults: recommendations for syndrome definition and measurement techniques in clinical research. The Report of an American Academy of Sleep Medicine Task Force. Sleep 1999;22:667-89.

13. Di Malta E. Basi Anatomo-Fisiologiche delle III Classi. Terapia Ortopedica. Bologna (Italy): Edizioni Martina; 1992.

14. Gianni E. La nuova Ortognatodonzia. Padova (Italy): Piccin; 1980.

15. Langlade M. Cefalometria Ortodontica. Milano (Italy): Scienza e Tecnica Dentistica; 1979. 
16. Pirelli P. Suture craniofacciali e ortognatodonzia: applicazioni cliniche [Craniofacial sutures and orthodontics: clinical applications]. Mondo Ortod 1996;21: 339-50 [in Italian].

17. Pirelli P, Giancotti A, Pirelli M. ERM: effetti strutturali e ripercussioni sul setto nasale [R.M.E. anatomical effects and responses of the nasal septum]. Mondo Ortod 1996;21:351-60 [in Italian].

18. Pirelli $\mathrm{P}$, Marullo M, Casagrande $\mathrm{M}$, et al. Espansione rapida del mascellare: effetti sulla funzionalità respiratoria ed uditiva [Rapid maxillary expansion: effects on the respiratory and auditive function]. Mondo Ortod 1995;20:129-35 [in Italian].

19. Timms DJ. The effect of rapid maxillary expansion on nasal airway resistance. Br J Orthod 1986;13(4):221-8.

20. Pirelli $P$, Arcuri $C$, Cocchia D, et al. Considerazioni sulla sinostosi della sutura mesiopalatina dell'uomo: studio istologico [Considerations on the synostosis of the human midpalatal suture: histological investigation]. Ortognatodonzia Italiana 1993;2(1):111-5 [in Italian].

21. Pirelli P, Botti F, Ragazzoni E, et al. Light microscopic investigation of the human midpalatal suture. Ital J Anat Embryol 1999;104(1):11-8.

22. Pirelli $P$, Botti F, Arcuri $C$, et al. New morphologic data on the human palatal suture [abstract]. Acts $72^{\circ}$ Congress-Eur Orthod Soc Brighton; 1996.

23. Timms DJ. The reduction of nasal airway resistance by rapid maxillary expansion and its effect on respiratory disease. J Laryngol Otol 1984;98(4):357-62.

24. Timms DJ. Rapid maxillary expansion in the treatment of nocturnal enuresis. Angle Orthod 1990;60(3):229-33 [discussion: 234].

25. Kurol J, Modin H, Bjerkhoel A. Orthodontic maxillary expansion and its effect on nocturnal enuresis. Angle Orthod 1998;68(3):225-32.

26. Warren DW, Hershey HG, Turvey TA, et al. The nasal airway following maxillary expansion. Am J Orthod Dentofacial Orthop 1987;91(2):111-6.

27. Guilleminault C, Li KK. Maxillomandibular expansion for the treatment of sleepdisordered breathing: preliminary result. Laryngoscope 2004;11(5):893-6.

28. Darendelirer MA, Lam LC, Pirelli P, et al. Dentofacial orthopedics. In: Lavigne GJ, Cistulli PA, Smith MT, editors. Sleep medicine for dentists. Canada: Quintessence books; 2009. p. 85-91, chapter 11. 